\title{
EDITORIAL Chiari malformation I surgically treated with atlantoaxial fixation
}

\author{
Andrew Jea, MD \\ Neuro-spine Program, Division of Pediatric Neurosurgery, Texas Children's Hospital; and Department of Neurosurgery, Baylor \\ College of Medicine, Houston, Texas
}

I $\mathrm{N}$ this issue of the Journal of Neurosurgery: Spine, Professor Atul Goel submits a single-institution, singlesurgeon retrospective analysis of 65 adult and pediatric patients with "complex" Chiari malformations (CMs), that is, CM Type I associated with complex bony anomalies of the craniocervical junction and brainstem compression. ${ }^{4}$ Professor Goel is respected as a clinical pioneer and thought leader for disorders at the craniocervical junction.

He asserts that the basic pathophysiological mechanism for $\mathrm{CM}$ with or without basilar invagination and with or without syringomyelia is $\mathrm{Cl}-2$ instability. This assertion challenges conventional theories. Bollo et al. ${ }^{1}$ recently thoroughly described this entity in the pediatric neurosurgical literature; the authors identified basilar invagination, CM 1.5 , and a clivoaxial angle $<125^{\circ}$ as patient risk factors necessitating reduction and occipitocervical fusion in addition to mandatory suboccipital decompression.

In the present study Goel speculates that $\mathrm{CM}$ and syringomyelia are "Nature's protective mechanism" of the body and compares CM to an "air bag." This speculation, at best, is unsupported and unsubstantiated by evidence in the study and the literature and, at worst, sounds flowery and sophomoric. This literary metaphor seems out of place in a scientific journal.

Professor Goel attempts to demonstrate in his series a new paradigm for treating symptomatic $\mathrm{CM}$, that is, $\mathrm{Cl}-2$ posterior instrumented fusion alone using $\mathrm{C}-1$ lateral mass screws and C-2 pars or pedicle screws - without any attempt at CM decompression and without occipitocervical fusion. Notably, in his series, there was one death $(1.5 \%)$ from vertebral artery injury (out of 3 total vertebral artery injuries; approximately 5\% rate of injury) while exposing entry points for the $\mathrm{C}-1$ lateral mass screws.

Professor Goel managed these patients with a C1-2 posterior instrumented fusion. As part of the preparation for placing the $\mathrm{C}-1$ lateral mass screws, anomalous vertebral arteries needed to be "dissected" away from the C-1 facet process. Why? This seems completely unnecessary and adds significant risk to the procedure (vertebral artery injury or spasm). The C-1 arch is already fused to the occiput in more than a few examples provided as figures; therefore, fusing from the occiput (with occipital screws and plates) to C-2 would be a biomechanically equivalent construct, without the loss of additional range of motion at the craniocervical junction and without having to manipulate the vertebral arteries.

Related to the above point, basilar invagination and/or platybasia are typically regarded as signs of craniocervical junction instability, and an occipitocervical construct is usually indicated. Moreover, in a subgroup of patients (Group A) in Professor Goel's study, cervical traction was applied intraoperatively "to reduce basilar invagination and restore craniovertebral alignment." How does a C1-2 fusion alone maintain this reduction? Again, occipitocervical fusion seems necessary to maintain this reduction.

Mortality rates for $\mathrm{CM}$ decompression surgery with or without duraplasty range from $0 \%$ to $0.9 \%$ in large series. ${ }^{5,6}$ Vertebral artery injury rates range from $0 \%$ to $0.7 \%$ for posterior fossa decompression with and without duraplasty for the surgical treatment of CM. ${ }^{2}$ Professor Goel's mortality rate and vertebral artery injury rate using this new surgical approach for CM seem alarmingly high, unjustified, and lie outside of published benchmarks for the surgical treatment of CM using suboccipital craniectomy plus or minus duraplasty.

While the patient-reported outcomes seem very satisfactory (63 [97\%] of 65) on health-related quality of life (HRQOL) outcome surveys (Japanese Orthopaedic Asso- 
ciation [JOA] and visual analog scale [VAS]-neck pain), these patient-driven outcome surveys have not been validated for CM. In fact, VAS-neck pain is a poor measure of outcome, with the loss of validity and responsiveness. ${ }^{3}$ The Neck Disability Index together with the 12-Item Short-Form Health Survey (SF-12) or EQ-5D is the most valid measure of pain and disability and quality of life in patients with CM-I. ${ }^{3}$ These outcome tools should have been considered in this study.

Nonetheless, Professor Goel should be lauded for his thinking outside the box. His study, while unconventional, could indeed be a significant contribution to neurosurgery and to our dawning knowledge of the natural history, pathogenesis, management, and surgical treatment of symptomatic $\mathrm{CM}$; however, much has yet to be elucidated. Large multicentered retrospective and prospective studies conducted through collaboratives, such as the Park-Reeves Syringomyelia Research Consortium, will be important to further clarify the complex relationships between CM, syringomyelia, and bony abnormalities at the craniocervical junction.

http://thejns.org/doi/abs/10.3171/2014.9.SPINE14893

\section{References}

1. Bollo RJ, Riva-Cambrin J, Brockmeyer MM, Brockmeyer DL: Complex Chiari malformations in children: an analysis of preoperative risk factors for occipitocervical fusion.

J Neurosurg Pediatr 10:134-141, 2012

2. Durham SR, Fjeld-Olenec K: Comparison of posterior fossa decompression with and without duraplasty for the surgical treatment of Chiari malformation Type I in pediatric patients: a meta-analysis. J Neurosurg Pediatr 2:42-49, 2008

3. Godil SS, Parker SL, Zuckerman SL, Mendenhall SK, McGirt MJ: Accurately measuring outcomes after surgery for adult Chiari I malformation: determining the most valid and responsive instruments. Neurosurgery 72:820-827, 2013

4. Goel A: Is atlantoaxial instability the cause of Chiari malformation? Outcome analysis of 65 patients treated by atlantoaxial fixation. J Neurosurg Spine [epub ahead of print Month Day, 2014. DOI: 10.3171/2014.10.SPINE14176]

5. Klekamp J: Surgical treatment of Chiari I malformationanalysis of intraoperative findings, complications, and outcomes for 371 foramen magnum decompressions. Neurosurgery 71:365-380, 2012

6. Tubbs RS, Beckman J, Naftel RP, Chern JJ, Wellons JC III, Rozzelle CJ, et al: Institutional experience with 500 cases of surgically treated pediatric Chiari malformation Type I.

J Neurosurg Pediatr 7:248-256, 2011

\section{Response}

\section{Atul Goel, MCh}

Department of Neurosurgery, King Edward VII Hospital and Seth G.S. Medical College, Parel, Mumbai, India

I thank Dr. Jea for his positive and negative remarks regarding my paper. His comments give me an additional opportunity to discuss the subtleties of the paper and elaborate on our understanding of the relatively complex subject.

Jea mentions that the paper discusses the issues in CM cases that are associated with complex bone lesions of the craniocervical region. I wish to clarify that cases of CM that are not associated with any morphological bone abnormality are also discussed in the paper. We understand that CM is "always" (excluding the cases mentioned in the text) associated with or is the result of atlantoaxial dislocation regardless of the presence or absence of bone anomalies in the region.

For several decades CM has been considered to be a pathological entity that occupies space and compresses critical neural structures at the craniocervical junction and needs direct surgical treatment by resecting the tonsils or by creating space for the tonsils through decompression via bone and dural release. A similar line of thought applies to syringomyelia, which has been considered, at least by some, as a space-occupying lesion that needs drainage. Given our analysis, we understand that both $\mathrm{CM}$ and syringomyelia are secondary results of subtle and longstanding atlantoaxial instability. ${ }^{1}$ As we continue to treat more such cases using only atlantoaxial fixation, we find that tonsils quite frequently migrate back to their original position and that the syrinx cavity collapses following a surgical procedure that focuses only on atlantoaxial fixation. Clinical recovery begins in the immediate postoperative phase and is remarkably significant. Such findings do validate our hypothesis and at least suggest that tonsils in CM are Nature's "air bag" that positions itself in the location as long as there is atlantoaxial instability. Nature's air bag protects the cord from getting pinched between bones in the event of instability. Similar thoughts appear to be valid for syringomyelia. Our earlier proposed concept that a reduction in the posterior cranial fossa volume causes tonsillar herniation ${ }^{4}$ does not seem to be valid, as we have observed that the cerebellum is more frequently atrophied in such cases. I agree that more multicentric studies are necessary to confirm such a divergent thought before any final conclusions can be drawn. I can only state that what seems like a poetic metaphor may just be fact.

We were among the first authors to describe the insertion of occipital screws in $1988 .{ }^{4,6}$ Despite this, we believe that screw fixation into the substance of the facet of the atlas that allows insertion of a 25-mm-long screw into the substance of firm "cortical" bone is remarkably stronger than the fixation of multiple small screws into the occipital squama, which ranges from 1 to $5 \mathrm{~mm}$ in thickness. However, exposure of the atlas for direct screw insertion is a formidable surgical task, particularly in cases with basilar invagination and in the presence of an occipitalized atlas. And on occasion, there can be danger to the vertebral artery. However, difficulty in the surgical procedure does not make it less ideal. If the procedure is difficult, it must be learned and perfected rather than supplemented by a long and potentially weak fixation construct that severely limits head movement and is likely to fail. We are convinced that the inclusion of occipital bone is a suboptimal form of fixation and can be easily avoided. Opening the atlantoaxial joint and stuffing bone graft within its confines not only provides stability to the construct but also fixes the region by itself and presents a large bone surface for bone fusion. ${ }^{2}$ It is crucial to understand that instability in such cases occurs at the atlantoaxial joint and not at the occipitoaxial joint. Fixating a joint that is not unstable harms the 
biomechanical strength of the construct and limits neck movements. We prefer atlantoaxial fixation even in cases with assimilation of the atlas. Such a short and focused fixation provides firm fixation and ground for bone fusion. Fixation with longer implants to include occipital bone screws can be avoided. We were the first ones to attempt reduction of basilar invagination by using occitocervical implants after cervical traction. ${ }^{2,3}$ However, we were not satisfied with such fixation, and reduction failed in all four cases in which it was used. ${ }^{3}$ Atlantoaxial facetal distraction and fixation provide a great opportunity for craniovertebral realignment and segmental stabilization. ${ }^{2}$ Such a concept has radically changed the treatment paradigm that is currently adopted for basilar invagination, ${ }^{2}$ and the previously considered "irreducible" dislocation ${ }^{5}$ and transoral surgical decompression is gradually but surely slipping into the domain of history.

I agree that the mortality rate in foramen magnum decompression surgery is 0 or close to 0 ; however, it does not mean that a safe and relatively "easy" surgery is better than rational and philosophically correct surgery that is more difficult.

\section{References}

1. Goel A: Is syringomyelia pathology or a natural protective phenomenon? J Postgrad Med 47:87-88, 2001

2. Goel A: Treatment of basilar invagination by atlantoaxial joint distraction and direct lateral mass fixation. J Neurosurg Spine 1:281-286, 2004

3. Goel A, Bhatjiwale M, Desai K: Basilar invagination: a study based on 190 surgically treated cases. J Neurosurg 88:962-968, 1998

4. Goel A, Desai K, Muzumdar D: Atlantoaxial fixation using plate and screw method: a report of 160 treated patients. Neurosurgery 51:1351-1357, 2002

5. Goel A, Kulkarni AG, Sharma P: Reduction of fixed atlantoaxial dislocation in 24 cases. Technical note. J Neurosurg Spine 2:505-509, 2005

6. Goel A, Laheri V: Plate and screw fixation for atlanto-axial dislocation. (Technical report). Acta Neurochir (Wien) 129:47-53, 1994 